\title{
Note
}

\section{Separation of Cesium: Adsorption and Desorption Properties of Hexacyanidoferrate(II)s Immobilized in Silica Gel}

\author{
Ryutaro $\mathrm{KAI}^{1}$, Kosuke UCHIYAMA ${ }^{1}$, Ben NANZAI ${ }^{1}$, and Manabu IGAWA ${ }^{1 *}$ \\ ${ }^{1}$ Department of Material and Life Chemistry, Faculty of Engineering, Kanagawa University, \\ Rokkakubashi, Kanagawa-ku, Yokohama, 221-8686 Japan
}

(Manuscript received May 31, 2014; Accepted July 8, 2014)

\begin{abstract}
The adsorption properties of cesium ion and potassium ion to iron(III) hexacyanidoferrate(II) (IF) and copper(II) hexacyanidoferrate(II) (CF) immobilized in silica gel were investigated. The selectivity of cesium to potassium and the maximum adsorption amount were about the same for these adsorbents, but some adsorption properties were different for these adsorbents. The adsorption amount was dependent on the counter anion species and proton was desorbed alongside the adsorption of cations for IF, while the adsorption amount was independent on the counter anion species and proton was not desorbed alongside the adsorption for CF. The adsorption amount increased with the temperature for both adsorbents and the dependence on the temperature for IF was much more significant than that for CF.
\end{abstract}

Keywords: Cesium, Hexacyanidoferrate, Separation, Silica gel

\section{Introduction}

Since the accident of the Nuclear Power Plant in Fukushima, various studies on the removal of the radioactive Cs have been reported. ${ }^{1,2)}$ Zeolite and titanium silicate are abundant in Japan and can be used as the adsorbent for cesium, but they do not have a large adsorption capacity and a high selectivity for cesium and their adsorption properties are affected by the acidity and basicity of the solution., ${ }^{3,4)}$ On the other hand, the hexacyanidoferrate(II)s have extremely high cesium selectivity, and are useful as the remover of cesium, ${ }^{5,6}$ because of the matching of the space in the lattice with the size of cesium ion. ${ }^{7)}$ Hexacyanidoferrate(II)s have a general formula of $\mathrm{A}(\mathrm{I})_{X} \mathrm{~B}(\mathrm{II})_{Y} \mathrm{C}(\mathrm{III})_{Z}\left[\mathrm{Fe}(\mathrm{CN})_{6}\right]_{W}(X+2 Y+3 Z=4 W)$, are crystalline ion exchangers, and are provided as the precipitates by adding the salt of transition metal ion such as iron, copper, and nickel to the aqueous solution of potassium hexacyanidoferrate(II). The hexacyanidoferrate(II)s are very small particulate matters and various methods are proposed to immobilize the hexacyanidoferrate(II)s on some gels, resins, cloths, and so on. ${ }^{1,8-11)}$

The adsorption properties of the immobilized hexacyanidoferrate(II)s should be investigated fundamentally for the practical use for the cesium removal. The desorption properties of the adsorbent are also important, because there are many materials adsorbing cesium selectively as hexacyanidoferrate(II)s in nature and their desorption properties should be known for the decontamination of the scattered radioactive cesium. Furthermore, the adsorption properties of the hexacyanidoferrate(II)s can be known in detail by the investigation of its desorption properties. In this paper, we will report the adsorption and the desorption properties of the hexacyanidoferrate(II)s supported in the silica gel for the specific adsorbent for cesium.

\section{Experimental}

\subsection{Preparation of Adsorbent}

The silica gel used in this paper is water resistant CARiACT Q (Fuji Silysia Chemical Ltd.), whose characteristics is as follows. The particle size is 1.70 to $4.0 \mathrm{~mm}$, the average pore diameter is $50 \mathrm{~nm}$, the pore volume is $1.00 \mathrm{~cm}^{3} \mathrm{~g}^{-1}$, the specific surface area is $68 \mathrm{~m}^{2} \mathrm{~g}^{-1}$, and the density is $0.41 \mathrm{~g} \mathrm{~cm}^{-3}{ }^{12)}$ The adsorbent was prepared by the method reported by Tanihara as follows. ${ }^{13)}$ Two grams of silica gel were immersed in an aqueous solution saturated with sodium hexacyanidoferrate(II)

*Corresponding author

E-mail: igawam01@kanagawa-u.ac.jp 
decahydrate (Kanto Chemical Co., Inc.) for $2 \mathrm{~h}$. The solution was removed, and the gel was rinsed with ethanol for some times. The crystal of sodium hexacyanidoferrate(II) was formed in the gel and its excess was removed by rinsing with ethanol. After drying the gel containing the crystal, the silica gel was immersed for $24 \mathrm{~h}$ in $20 \mathrm{~mL}$ of ethanol containing dissolved iron(III) chloride or copper(II) chloride approximately eight times as much at a molar ratio as sodium hexacyanidoferrate(II) in the silica gel. The ethanol was removed and the silica gel was dried for $6 \mathrm{~h}$ in a drying machine at $60{ }^{\circ} \mathrm{C}$ for $6 \mathrm{~h}$ to age the crystal. The gel was rinsed with water under an ultrasonic cleaner until hexacyanidoferrate(II)s did not leak out from the gel. The gel was dried in a desiccator with slica gel desiccant. The mass of immobilized hexacyanidoferrate(II)s was 0.26 to $0.28 \mathrm{~g}$ in $2 \mathrm{~g}$ of silica gel for iron(III) hexacyanidoferrate(II) (IF) and 0.29 to $0.33 \mathrm{~g}$ in $2.0 \mathrm{~g}$ of silica gel for copper(II) hexacyanidoferrate(II) (CF).

\section{2-2 Adsorption and Desorption Experiment}

The adsorption and desorption properties were measured by batch tests. The $2.0 \mathrm{~g}$ of the silica gel and ca. $0.3 \mathrm{~g}$ of the immobilized hexacyanidoferrate(II)s in the gel was immersed in $200 \mathrm{~mL}$ of the mixed aqueous solution of $1 \mathrm{mmol} / \mathrm{L}$ cesium chloride and $1 \mathrm{mmol} / \mathrm{L}$ potassium chloride, unless otherwise stated. In the experiment of the effect of concentration, that is Fig. 1, the concentration was changed from $1 \mathrm{mmol} / \mathrm{L}$ to 10 mmol/L. Adsorption experiments were carried out for $24 \mathrm{~h}$ in a shaking incubator (Tokyo Rikakikai Co., Ltd., EYELA EI-10). The concentration change in the adsorption experiment was determined by using an atomic absorption spectrophotometer (Shimadzu Co., AA-6700F) to obtain the adsorbed amount of the cation in the adsorbent. The solution $\mathrm{pH}$ was measured by using a $\mathrm{pH}$ meter (Toa Electronics Co., HM-60S). When the effect of the counter-anion of the cesium and potassium on the adsorption of the two cations was investigated, fluoride, bromide, and iodide salts of cesium and potassium were also used other than chloride salts. The anion concentration change in the salt solution during the adsorption experiment was determined by using an ion chromatograph (Dionex Co., DX120) with the column for anion analysis (Dionex Co., IonPac AS12A).

The desorption experiment was carried out by using $2.0 \mathrm{~g}$ of the silica gel and ca. $0.3 \mathrm{~g}$ of the immobilized hexacyanidoferrate(II)s after the adsorption to the gel with 200 $\mathrm{mL}$ mixed solution of $1 \mathrm{mmol} / \mathrm{L}$ cesium chloride and $1 \mathrm{mmol} / \mathrm{L}$ potassium chloride. After washing and drying the silica gel and hexacyanidoferrate(II)s immobilized in the gel adsorbing cesium and potassium, they were immersed in $100 \mathrm{~mL}$ of $0.1 \mathrm{~mol} / \mathrm{L}$ nitric acid aqueous solution unless otherwise stated for $24 \mathrm{~h}$ in the shaking incubator. When the effect of $\mathrm{pH}$ was investigated, nitric acid or an organic acid diluted to a certain $\mathrm{pH}$ was used. The effect of the cation species on the desorption of cesium was investigated by using $0.1 \mathrm{~mol} / \mathrm{L} \mathrm{NH} \mathrm{NH}_{4} \mathrm{Cl}, 0.1 \mathrm{~mol} / \mathrm{L} \mathrm{KCl}, 0.1$ $\mathrm{mol} / \mathrm{L} \mathrm{NaCl}$, or pure water, where solution volume and the amount of adsorbents were the same as the case of $0.1 \mathrm{~mol} / \mathrm{L}$ $\mathrm{HNO}_{3}$ noted above. The equilibrated solution was analyzed after the desorption experiment and the ratio of the desorbed amount to the initial adsorbed amount was evaluated as the desorption ratio.

\section{Results and Discussions}

\subsection{Adsorption properties}

The concetration dependencies of the adsoption of cesium to iron(III) hexacyanidoferrate(II) (IF) and copper(II) hexacyanidoferrate(II) (CF) were observed by using cesium chloride solution. Langmuir equation shown in Eq. 1 can be applied to the adsorption to the both adsorbents. ${ }^{4)}$

$$
\theta=\frac{A}{A_{\max }}=\frac{b\left[\mathrm{Cs}^{+}\right]}{1+b\left[\mathrm{Cs}^{+}\right]}
$$

where $\theta$ is the coverage factor, $A$ is the adsorbed amount of ion from the aqueous solution per the adsorbent amount immobilized in silica gel, $A_{\max }$ is the maximum adsorbed amount, $b$ is the binding constant, and $\left[\mathrm{Cs}^{+}\right]$is the concentration of cesium in the adsorption equilibrium aqueous solution. Equation 2 can be obtained from Eq. 1 and the linear relationship estimated from Eq. 2 can be obtained for these two adsorbents as shown in Fig. 1.

$$
\frac{\left[\mathrm{Cs}^{+}\right]}{A}=\frac{\left[\mathrm{Cs}^{+}\right]}{A_{\max }}+\frac{1}{b A_{\max }}
$$

From Eq. 2 and Fig. 1, we can obtain $A_{\max }$ for IF were 0.67 $\mathrm{mmol} / \mathrm{g}$ and for CF were $0.69 \mathrm{mmol} / \mathrm{g}$. Although the formulas of $\mathrm{CF}$ and IF used in this study are not certificated, the molar ratio of the maximum adsorbed amount of cesium to iron(III) hexacyanidoferrate(II) was about the same as the value reported for the prussian blue nanoparticle. ${ }^{6}$

The effect of temperature on the adsorption amount was

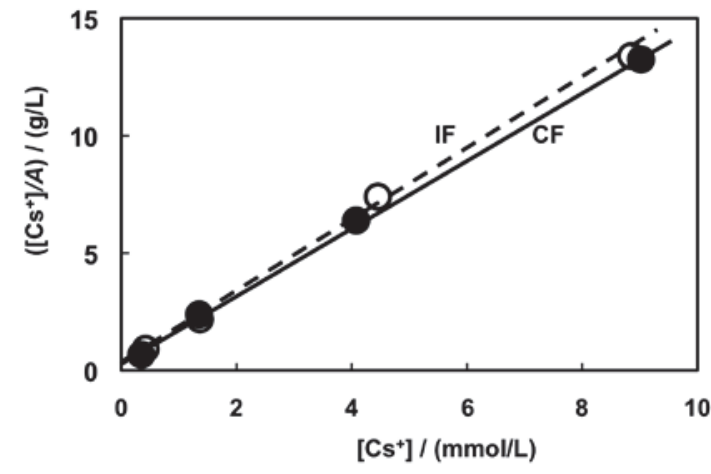

Fig. 1 Langmuir plots; $\boldsymbol{A}$ is adsorption amount of cesium on adsorbent, $\left[\mathrm{Cs}^{+}\right]$is equilibrium concentration of cesium, and IF and CF are iron(III) and copper(II) hexacyanidoferrate(II), respectively. 


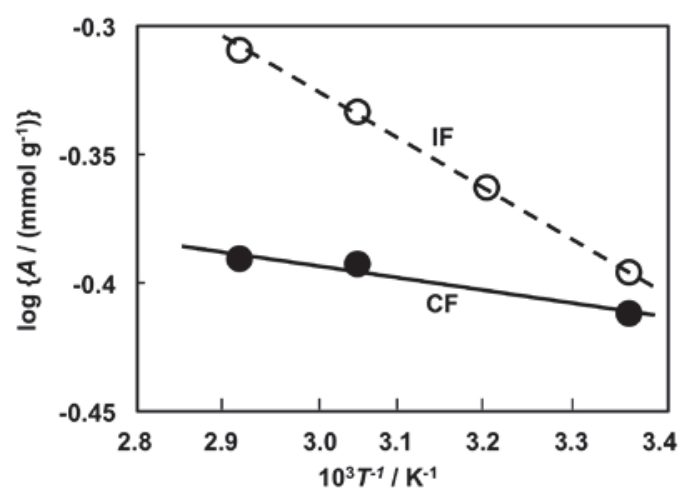

Fig. 2 Effect of temperature; $A$ is adsorption amount of cesium on adsorbent, and IF and CF are iron(III) and copper(II) hexacyanidoferrate(II), respectively.

investigated by using mixed solution of $1 \mathrm{mmol} / \mathrm{L}$ cesium chloride and $1 \mathrm{mmol} / \mathrm{L}$ potassium chloride and the results for cesium for both adsorbents are shown in Fig. 2. The adsorption amount increased with the temperature for IF, although it hardly increased for CF. The adsorption amount decreases with the temperature in general, but it increased with it in Fig. 2, which suggests that the adsorption of cations into the adsorbents are caused by ion exchange instead of the general surface adsorption. The dependencies of potassium ions on the temperature were not observed for these adsorbents. From the slope in Fig. 2, the adsorption enthalpies for IF and CF were calculated to be $3.7 \mathrm{~kJ} \mathrm{~mol}^{-1}$ and $0.97 \mathrm{~kJ} \mathrm{~mol}^{-1}$, respectively.

The adsorption amounts of these adsorbents are dependent on the radius of the cation, and they have the maximum amounts for cesium among the alkali metal ions. The adsorption amounts also depend on the counter anion species. Figure 3 shows the adsorption amounts of halide salts of cesium and pottasium as the function of the anion radius ${ }^{14)}$. The adsorption amount of cesium was larger than that of pottasium, and the source phase

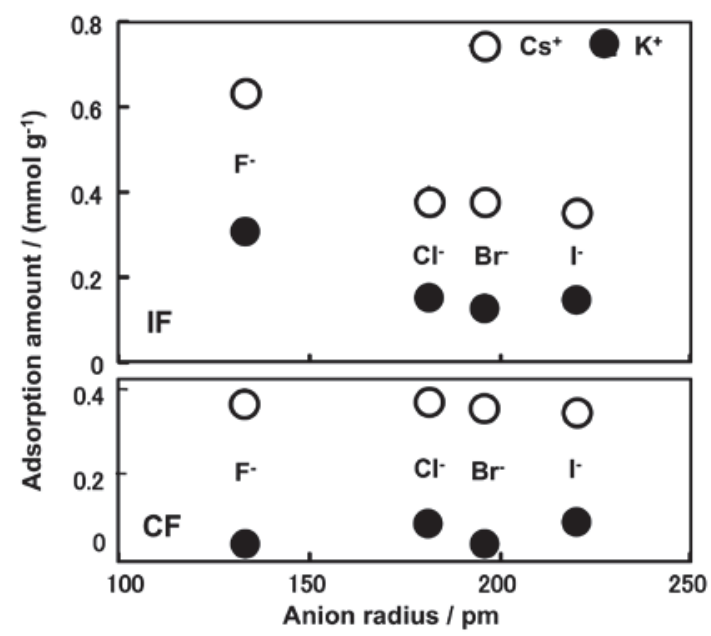

Fig. 3 Effect of anion radius on adsorption amount; IF and CF are iron(III) and copper(II) hexacyanidoferrate(II), respectively.
Table 1. Solution pH before and after adsorption to IF and CF.

\begin{tabular}{|c|c|c|c|c|}
\hline Salt & CsF-KF & $\mathrm{CsCl}-\mathrm{KCl}$ & $\mathrm{CsBr}-\mathrm{KBr}$ & CsI-KI \\
\hline Time & $0 \mathrm{~h} \quad 24 \mathrm{~h}$ & $0 \mathrm{~h} 24 \mathrm{~h}$ & $0 \mathrm{~h} 24 \mathrm{~h}$ & $0 \mathrm{~h} 24 \mathrm{~h}$ \\
\hline $\begin{array}{l}\mathrm{pH} \text { for IF } \\
\mathrm{pH} \text { for } \mathrm{CF}\end{array}$ & $\begin{array}{ll}5.83 & 4.36 \\
5.84 & 5.65\end{array}$ & $\begin{array}{ll}5.70 & 3.28 \\
5.88 & 5.59\end{array}$ & $\begin{array}{ll}5.54 & 3.24 \\
5.72 & 5.67\end{array}$ & $\begin{array}{ll}5.64 & 3.41 \\
5.07 & 5.58\end{array}$ \\
\hline
\end{tabular}

IF and CF are iron(III) and copper(II) hexacyanidoferrate(II), respectively.

solution became acidic for IF. In the case of fluoride salts, the adsorption amount was larger than those of other halide salts, and the desobed proton amount was much smaller than others as shown in Table 1. In the crystal lattice of IF, water molecule is captured, ${ }^{15)}$ and hydrogen ion has not been reported to be one of the lattice ions in IF. Therefore, it can be speculated that the cations in the solution is exchanged with proton from the water molecule in the crystal lattice. The ion exchange of cesium with proton in IF was also reported recently by Ishizaki et al. ${ }^{16)}$ The adsorbed amount of cesium was comparable with the desorbed amount of proton except for fluoride salts. In the case of fluoride salts, the $\mathrm{pH}$ lowering is small. The $\mathrm{pKa}$ value of hydrofluoric acid is $3.20,{ }^{17)}$ and the content of the undissociated hydrofluoric acid was very small at $\mathrm{pH} 4.36$, the solution $\mathrm{pH}$ after the adsorption experiment. The fluoride ion is estimated to be adsorbed into the adsorbents on the view of the electroneutrality. Then, fluoride ion was measured in this experiment and it was confirmed that the adsorbed fluoride ion amount was approximately equal to the total amount of adsorbed cations. On the other hand, there was no dependence on the halide anion species for $\mathrm{CF}$ and the $\mathrm{pH}$ did not change alongside the adsorption, while the selectivity of

cesium to potassium was higher that that of IF. The adsorption mechanism of these two adsorbents are different to each other and it was also dependent on the counter anion in the case of IF.

\subsection{Desorption properties}

Desorption properties of cesium and potassium adsorbed on these adsorbents were investigated by using nitric acid. Figure 4 shows the effect of the initial solution $\mathrm{pH}$ on the desorption

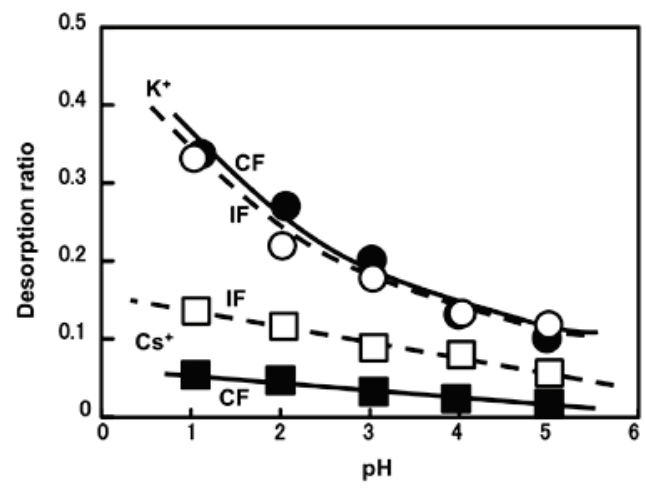

Fig. 4 Effect of pH on the desorption ratio; desorption ratio is defined as the ratio of the desorbed amount to the initial adsorbed amount on the adsorbent, and IF and CF are iron(III) and copper(II) hexacyanidoferrate(II), respectively. 


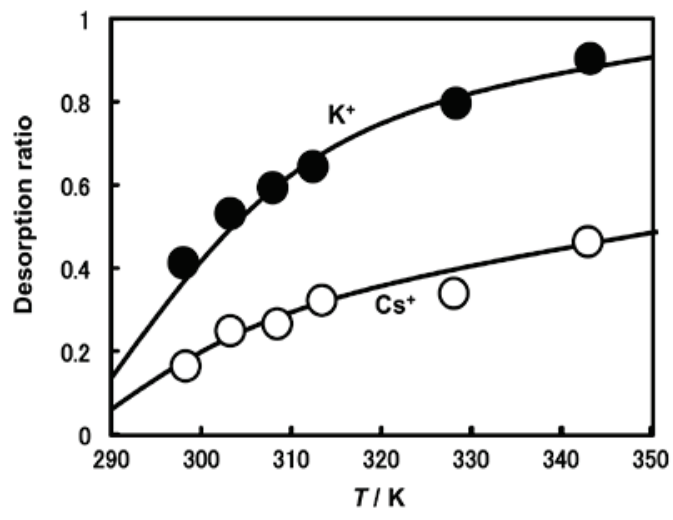

Fig. 5 Effect of temperature on the desorption of ions adsorbed on iron(III) hexacyanidoferrate(II); desorption ratio is defined as the ratio of the desorbed amount to the initial adsorbed amount on the adsorbent.

ratio, which is defined as the ratio of the desorbed amount to the initial adsorbed amount on the adsorbent. Desorption ratio decreased with $\mathrm{pH}$ for potassium and cesium. The trend is the same for both adsorbents, although the desorption ratio of cesium for IF is larger than that for CF. The desorption ratio was also investigated by using acetic acid, and the behavior is the same as the case of nitric acid for these two adsorbents, which means that the desorption ratio is dependent on $\mathrm{pH}$ and independent on the acid concentration and acid species.

The effect of the cation species on the desorption of cesium was investigated and the desorption ratios were as follows: $\mathrm{NH}_{4} \mathrm{Cl}(0.15)>\mathrm{HNO}_{3}(0.12)>\mathrm{KCl}(0.085)>\mathrm{NaCl}(0.036)>>$ pure water $(0.0029)$ for IF and $\mathrm{NH}_{4} \mathrm{Cl}(0.10)>\mathrm{HNO}_{3}(0.066)>$ $\mathrm{KCl}(0.059)>\mathrm{NaCl}(0.025)>>$ pure water $(0.00063)$ for $\mathrm{CF}$, where the values in the parentheses were the desorption ratio after $24 \mathrm{~h}$. Ammonium ion was effective for the desorption of cesium for these two adsorbents, which may be caused by its large ion radius.

The effect of temperature on the desorption ratio was investigated for these two adsorbents by using $0.1 \mathrm{~mol} / \mathrm{L}$ nitric acid, and the result is shown in Fig. 5. The temperature dependence for potassium was much larger than that of cesium, but the desorption ratio increased with temperature for both of the cations adsorbed on IF. The desorption ratio hardly increased with temperature for the cations adsorbed on CF. The desorption efficiency of the adsorbed cesium increased with the lowering of $\mathrm{pH}$ and the elevation of temperature in the case of IF, while the desorption efficiency of the adsorbed cesium was scarcely affected by $\mathrm{pH}$ and temperature in the case of $\mathrm{CF}$.

\section{Conclusion}

Hexacyanidoferrate(II)s are very important adsorbents for the decontamination of the radioactive cesium, but their adsorption properties are complicated. The properties are much dependent on the counter cation of the hexacyanidoferrate(II), and the adsorption amounts of cesium on the typical hexacyanidoferrate(II), IF, are dependent on the counter anion of cesium. For the decontamination of the radioactive cesium, the adsorption and desorption characteristics should be investigated further and their characteristics should be utilized effectively in the decontamination.

\section{References}

1) I. Sato, H. Kudo and S. Tsuda, J. Toxicol Sci., 36, 829 (2011).

2) W. Amakai, M. Sugiyama, K. Fujiwara, T. Sugo, D. Umeno and K. Saito, Bull. Soc. Sea Water Sci., Jpn., 68, 18 (2014).

3) E. H. Boral, R. Harjula, Leena maline and A. Paajanen, J. Hazardous Materials, 172, 416 (2009).

4) F. Han, G. H. Zhang and P. Gu., J. Radioanal. Nucl. Chem., 295, 369 (2013).

5) J. Lehto, R. Harjula and J. Wallance, J. Radioanal. Nucl. Chem., 111, 297 (1987).

6) N. L. Torad, M. Hu, M. Imura, N. Naito and Y. Yamauchi, J. Mater. Chem., 22, 18261 (2012).

7) T. Matsuda, J. Kimb and Y. Moritomo, Dalton Trans., 41, 7520 (2012).

8) H. Mimura, J. Lehto and R. Harjula, J. Nucl. Sci. Technol., 34, 484 (1997).

9) H. Mimura, J. Lehto and R. Harjula, J. Nucl. Sci. Technol., 34, 582 (1997).

10) H. Mimura, M. Kimura, K. Akiba and Y. Onodera, J. Nucl. Sci. Technol., 35, 392 (1998).

11) Z. Du, M. Jia and X. Wang, J. Radioanal. Nucl. Chem., 298, 167 (2013).

12) Analytical table provided by Fuji Silysia Chemical Ltd.

13) K. Tanihara, Jpn. Patent, 11-76807 (1999).

14) "Handbook of Chemistry and Physics" (Ed. D. R. Lide), CRC Press, $84^{\text {th }}$ Ed., Boca Raton (2002-2003), 12-14.

15) F. Herren, P. Fischer, A. Ludi and W. Hälg, Inorg. Chem., 19, 956 (1980).

16) M. Ishizaki, S. Akiba, A. Ohtani, Y. Hoshi, K. Ono, M. Matsuba, T. Togashi, K. Kanaizuka, M. Sakamoto, A. Takahashi, T. Kawamoto, H. Tanaka, M. Watanabe, M. Arisaka, T. Nankawa and M. Kurihara, Dalton Trans., 42, 16049-16055 (2013).

17) "Handbook of Chemistry and Physics" (Ed. D. R. Lide), CRC Press, $84^{\text {th }}$ Ed., Boca Raton (2002-2003), 8-46. 